GLOBAL JOURNAL OF EDUCATIONAL RESEARCH VOL 13, 2014: 23-29

COPYRIGHT@ BACHUDO SCIENCE CO. LTD PRINTED IN NIGERIA. ISSN 1596-6224 www.globaljournalseries.com; Info@globaljournalseries.com

\title{
WHAT AUTONOMOUS PRACTICES DO HIGH PERFORMING STUDENTS USE WHEN PREPARING FOR EXAMINATION? A QUALITATIVE STUDY
}

\section{BERNEDETTE U. CORNELIUS-UKPEPI AND RITA A. NDIFON}

(Received 18, January 2014; Revision Accepted 18, February 2014)

\begin{abstract}
This qualitative study was designed to investigate autonomous practices employed by students who have scored high in the General Teaching Methods examination. Sixteen students who scored from $70 \%$ to $100 \%$ were selected for the study. They were asked to respond to four questions about their study practices. This paper reports an analysis of the students' responses to item one: "Tell us the story of how you prepared for examination." Written responses were analyzed for significant patterns and themes indicating successful study practices. The presenters discussed implications for working with students who are preparing for examination and highlight the inferences of this study for faculty.
\end{abstract}

KEYWORDS: Autonomous practices, high performing students, qualitative study, examination preparation

\section{INTRODUCTION}

Determination to pass examination is the sole responsibility of the student and this depends on how well a student prepares to achieve success in his/her examination. In Nigeria and at University of Calabar, there are many incidences of examination failure. It maybe that, students do not read adequately or teachers do not teach well. Most of the blame is normally apportion to the teachers but no one has stopped to check whether students do their own part of reading. During the past seven years as examination officers, we have observed when preparing students' results that very few students graduate due to failure rate and the ones who graduate have neither a carryover nor dropped course during their tenure in school. We wanted to find out about the autonomous practices used by a sampling of successful students. This qualitative research was conducted in an effort to find out what practices sixteen high scoring students employed to pass well in the last general teaching method examination. We hoped that this would enable us to give advice to other students who are lagging behind. Accordingly, St. Louis (2003) says that there is need to make students aware of the hidden potentials within and to find ways in which this can be exploited.

Smith (2003) asserts that for a student to be successful he/she must direct his/her energy towards activities that will enhance their chances for success. Cornelius-Ukpepi (2010) affirms that if students want to pass any examination they must attend classes regularly and pay attention in class, take down notes and mark areas or points stressed by lecturers. The author says that preparation of timetable, reading well in advance and making your personal jotter are important activities learners can engage themselves to become autonomous learners. This research confirms that these are strategies that can contribute to examination success.

\section{Method}

We invited sixteen students who scored between $70 \%-100 \%$ in the general teaching method examination in 2010/ 2011 session to take part in

Bernedette U. Cornelius-Ukpepi, Department of Curriculum and Teaching, University of Calabar, Calabar, Nigeria.

Rita A. Ndifon, Department of Curriculum and Teaching, University of Calabar, Calabar, Nigeria. 
the study. The instrument used to gather data consisted of four questions. The students were given 10 minutes to attempt each question on the answer booklet.

The questions are as follows:

1. Tell me a story on how you prepared for examination.

2. Did anyone give you a good advice on how to prepare for examination?

3. What advice would you offer to someone about to prepare for examination?
4. What is your favourite study strategy and why? A preliminary study of one question was carried out. During the administration, the students were given 10 minutes to respond to each question. The questions were taken one after the other. In this preliminary study report of question one, the data was coded for patterns and themes. Colored pencils were used to track patterns in the students' responses. Patterns were then clustered into themes which were arranged on a timeline, thus:

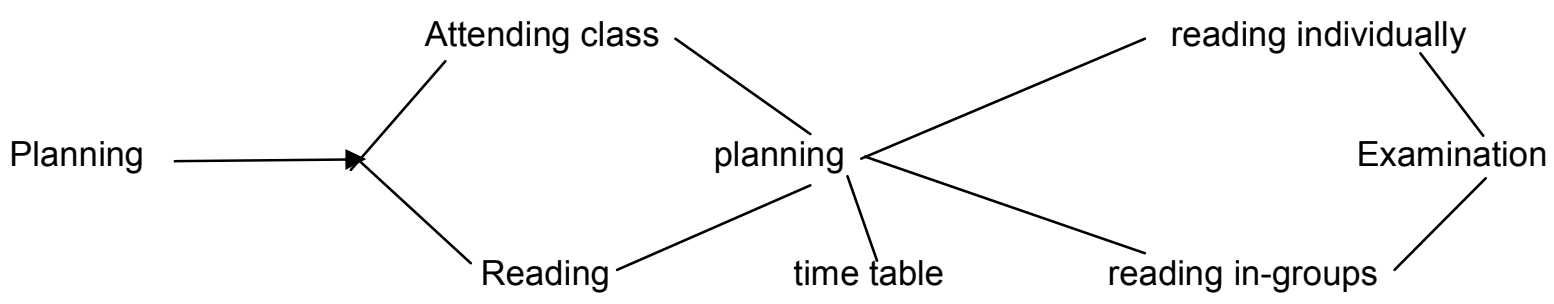

\section{Data Analyses}

It is interesting to note that these high scoring students started by planning at the beginning of the semester, well ahead of time. This initial planning appears to be a powerful strategy which helps them to score high.

They moved into attending classes and reading. Then, they started planning for the examination by developing a personal timetable to guide them, after which they began to read individually employing different strategies like, reading individually, going to the library, browsing, using acronyms and also participate in group reading. Finally they entered into examination.

\section{RESULTS AND DISCUSSION}

From the analyses of the data the following results emerged.

\section{Class Attendance}

In their responses, twelve of the sixteen students indicate the importance of class attendance. Their statements reveal a strong sense of the importance of attendance. For example:

- Preparing for an examination starts from the onset... with the first class attended.
- I prepare for my examination by attending lectures, not assuming that $I$ already know the course, no matter how familiar I am with the course.

- I make sure I am always in the class to listen and make notes.

- I ensure that I attend all my classes.

Although some respondents speak of attending "all classes," other set percentage goals for attendance:

- I must attend seventy percent of all the lectures in my course.

- [I] attend classes regularly, at least $75 \%$ in a given semester.

One student notes:

- I usually make better grades when I like my lecturer because I always want to attend his or her class without missing a single day.

The lecturers at the University of Calabar have observed that the rate of class attendance is very low, but many students will come for examination. For example, of a class with 400 students registered, only about 100 may come 
regularly for class, but 400 will show up for examination. Then, the pass rate is very low, while failure rate is high. The data of this small study suggest a correlation between attendance and examination success.

In their discussions of how they prepare for examination, some students talk about not only being in class but how to be in class, what to do there. For example:

- [l] ask questions in the class....

- I prepare for my examination by asking questions in the class because I will also ask a question I think it will be difficult for me to answer.

- I partake in the class continuous assessment.

Over half of the students wrote of the importance of taking down notes and how these notes become useful later.

- I make sure I listen to what my lecturer says and take notes.

- I will make notes from my textbook, read them and later compare them with the jottings I have been making in class.

- I try to reduce my notes into key points which I can easily remember.

- [l go] through my notes after lectures.

- I must read all my notes I jot down during lecture time.

- I read [my] notes line by line consistently.

As lecturers, we have observed that during class, some students take down notes while we are teaching and others do not. Some ask questions for clarification, and others do not even respond to questions asked by the lecturer. Clearly, these successful students in this study believe that it is important to not simply be in class but to be in class actively.

\section{Time Management}

Seven students reveal that timing of every activity both at the beginning of the semester and at the beginning of the examination is very important. Some of their statements:

- I try my best to resume on time, do my registrations, and pay my fees. All these will help me settle down well and start preparing for my academic work.

- Also students set a plan guide for each semester to read before examination.
- Preparation for an examination starts from the onset or beginning of the semester [by] attending the first class, then and there, you find the lecture interesting and prepare your reading time table (i.e. before examination).

Half of the students indicate that having a personal time table is very important for example

- During the preparation of my examination,... make a time table for myself which I paste on my wall close to my bed, my bed is the most special place to me in the entire house so I paste my time table beside it for easy access.

- Prepare a situated time table on all the courses I have.

- The second step involves a planned time table on how and when to study; it involves time allocation, interest and dedication.

- Prepare your reading time table (i.e. before examination)

Three students note that planning aids success. Their statements revealed the significance of planning at the beginning of examination.

- Firstly, planning is one of the key factors, if one fails to plan, he plans to fail, and thus planning is a major factor. Your planning for examination should start from your personal time....

- During the preparation of my examination, the first thing I do is to get my course outline and read through the outline. I pick out the important topics that the lecturer discussed in class, copy my exams time table and make a time table for myself.

Furthermore, seven students reveal that planning at the beginning of the course is very crucial:

- [l] acquire the necessary or prescribed text books or handouts.

- First of all, I prepare for my examination by resuming school early so as not to miss any class.

- Preparation for examination starts from identifying the course of study, the course contents and then organizing the course reading (study) materials.

It is pertinent to note here that these high scoring students are good time managers. 


\section{Reading and revising}

Virtually all of the students in this study addressed in one way or the other the importance of reading books and reading class notes throughout the term. Several are explicit in stating that reading should not be postponed until the examination period:

- I make sure I start reading my books early enough at the beginning of each semester.

- As a student that wants to make it in any course or programme, it is wise to study or read in advance before the week or day of examination. It is very unwise as a student not to study or read your book until the night or day to examination.

- I read and prepare for my examination a month before it comes up, and a week to my examination, I do my revision.

- After each lecture I always go for my personal research and read everything that I have been taught by the lecturer....

- I make sure I read what I did during class.

A few students indicate that they search for reading materials beyond textbooks:

- I do extensive research because some textbooks we use in school have limited scope....

- Aside my lectures, buying of textbooks, I also browse the internet to source for more information.

- I browse some things I need more information on.

As the examination period approaches, students indicate a need for specific strategies for preparation. Many of them speak of revision:

- You must revise all the contents in question as well as anticipating the questions you are prepared for.

- I do my revision, and keep glancing through my notebook and textbook.

- When the examination timetable is out, I read my textbook and notebook especially. This would be more of a revision.

- To understand and comprehend a particular concept (it is) required that the individual learner has to spend much time going through his study materials over and over again. This will help to promote good retention and recall during examination. This means that, the concept read must be put in the cue (arranged in the memory) before entering examination.

Others advise to "read your notes line by line, consistently," "develop quality time to [your] books," and "never play with your studies hours or period." One writes, "Imbibe reading culture and ensures that $90 \%$ of what you have read and revised is conversant with you."

Several respondents speak of reading during the night or in the early morning hours:

- When it is a night to my examination, I sleep and wake up at 5 am to do some revision before going for the examination (i.e. to help me [re]fresh my memory of what I have already read).

- I wake up at night when everyone is asleep and read my books precisely around $4 a m$ and stop by 6am to carry out my house chores. I spend every two hours at night to study my books.... If I read in a noisy environment, I hardly understand, so I try to avoid such places....

- A night to my examination, I try to read throughout the night and some hours before I start the exams. If I read and it is as if I am forgetting what I have read, I close my books and just rest my head for some time, so that in trying to add more I don't forget the ones I have read.

Many students report very specific strategies for preparing for exams. Their strategies include note making, question setting, acronyms, consultation of past questions, and group reading.

Approaches to note making vary. For example:

- I summarize every textbook connecting to the subject into my own level of understanding.

- I note down points while reading. I break down the topic to small logical forms.

- I bring out a sheet of paper for each of my courses, rule a line in the middle, jot down the important points after which I will read it over and over for retention.... 
Three students mention setting practice questions for themselves in anticipation of the examination:

- During examination period, I read and set questions for myself.

- I always...frame questions for myself to answer after reading.

- I set questions for [myself] relating to the subject $[\mathrm{l} \mathrm{am}]$ preparing for.

Acronyms are important strategy for two students:

- I use acronyms to reduce the work load and I make sure I memorize the acronyms to the best of my ability and it becomes my stream of knowledge and remembering.

- If there are series of points under a particular topic, I use acronyms to arrange them in order not to forget.

Over a third of the respondents indicate that consultation of past examination questions was a significant part of their approach to preparation for examination:

- I get past question papers from my seniors to enable me to know the pattern of questions to expect.

- I will pick past question papers, try to answer them and correct myself after answering them.

- I ask for past question papers...to enable me to know how the questions may look....

- I consult the past questions papers in my courses.

- It is also advisable to go through past question papers...in order to know the lecturer's pattern of setting questions.

Half of the high scoring students in this study made clear that group reading and group study are important elements of their success. For example:

- One of the things that have made me pass my examination is group reading...studying together and sharing of ideas help a lot. This is because most students find it difficult to understand lecturers in class but learn faster while studying among themselves.
- I try to involve myself in group discussions with other students including my immediate senior colleagues.

- The ability to interact can make the students group themselves and bring out each other's ideas and work on them.

\section{During examination}

Two students indicate the significance of avoiding noise and distraction:

- During examination I sat quietly on a convenient desk where noise is free with little amount of ventilation.

- After preparation, at examination venue I make sure I am not disturbed by noise and gist from friends

One student says,

- I make sure I finish before the allotted time to go through my work to convert my errors and in that process, the other become a clue to the one I regarded most difficult. More-so, since some questions had some rudiment of answers to the other questions. I read questions strictly and compare where necessary.

Another student is of the opinion thus:

- Another way I try to know the lecturer's area of interest is by "seeing them in my mind's eye" including all the illustrations, repetitions and examples, especially where the lecturer had used the phrase "take note."

This has implications for the lecturers, for it shows that teaching with illustrations, demonstrations and examples may help some students to remember what they have been taught.

\section{Autonomous learners}

The term autonomy refers to being independent of teachers and parents or anybody. This does not mean that the teacher's input is not needed. Holec (1991) defined autonomy as the ability of the learner to take charge of his/her learning. Autonomous learners must want to learn and develop metacognitive capacity which allows them to handle change, negotiate with others, and make strategic use of the learning environment (Breen and Mann, 1997). The statements of the sixteen high scoring students in 
our sample are consistent with this definition. These students clearly did take charge of their learning. They consciously developed strategies that worked for them individually and in groups. They were strategic time managers from the beginning of the semester through final examination. Furthermore, Dam (2000) sees autonomy in terms of creating an atmosphere conducive to learning within the confines of educational system.... These high scoring students indicate that they do avoid noise and distractions, staying in a quiet corner to read and reading at night.

\section{Educational implications of the study}

This study has implications for students as well as for lecturers. Lecturers can advise students to make use of the following strategies, each of which has been part of the success of students who have gone before them:

1. Preparation for examination starts right from the beginning of the semester by getting all the required reading materials.

2. Attending all the classes, taking down notes, participating actively in class and asking questions where necessary.

3. Reading and revising notes and textbooks, making notes, use acronyms as well as reading at night.

4. Develop a personal time table and make use of it.

5. Form reading groups to exchange ideas with classmates and senior students.

6. Avoid noise and distractions while reading

7. Finish exams early so as to go through to correct errors.

8. Make use of past exams question papers.

9. Browse the internet for more information. Lecturers might also consider teaching using a variety of illustrations; demonstrations and examples to enable students remember what they have been taught. This may help them to recall exactly how the lecturer demonstrates in class while teaching. Two students made mention of demonstrations and illustrations, of "seeing the lecturer in their mind's eyes." We feel that it is something lecturers may think about. Instructors may also consider being more open to students and allowing them to ask questions on issues that are not clear to them. For instance, one student said, "I always build up courage... to meet with the lecturer. Some students have the fear of meeting with the lecturer one [on] one which can reduce their understanding". We have often observed that during lecture, students loiter along the corridors of lecture halls. This causes noise and distractions to students who may want to read in those lecture halls. This study reveals that for some students, noise and distraction are detours away from examination success. Consequently, if there are things instructors can do to reduce noise and distractions it may be advisable to do so.

\section{Suggestions for further research}

Additional research into the autonomous practices of students preparing for examination may be useful in constructing a fuller picture of successful examination preparation. Future researchers may want to investigate the practices of low scoring and failing students, as well, in order to determine if there are significant differences in how they prepare. It might be worthwhile to provide a workshop for students in which not only lecturers but also previously high scoring students assist students with developing strategies for preparation; the results of such a workshop might then be studied in order to determine if it has had any effect. Any additional research into students' experiences of exam preparation that can lead us to deeper understanding of successful and unsuccessful practices will be of value as we seek successful outcomes for greater numbers of students.

\section{REFERENCES}

Breen, M. P and Mann, S. J., 1997. Shooting arrows at the sun: Perspectives on a pedagogy For autonomy in Benson, p., \& Voller, P. (ed) Autonomy \& Independence in language Learning. Harlow: Addison Wesley Longman Ltd, 132-149.

Cornelius-Ukpepi, B. U., 2010. Effective reading for passing internal and external examinations. Calabar: Hodo MPCS Ltd.

Dam, L., 200. Evaluating autonomous learning. In Sinclair, B., MacGrath, L., \& lamb,T. Learner autonomy, Teacher autonomy. Future directions. Harlow: pearson Education Limited, 48-59. 
Holec, H., 1981. Autonomy in Foreign languages learning. Oxford: Pergamon.

Smith, B. D., 2003. Bridging the gap: College Reading. Boston, Massachusetts: Pearson Longman.

St.Llouis, S., 2003. Helping students becoming autonomous learners: can technology help? 